\title{
Effects of hypoxic exercise training on microRNA expression and lipid metabolism in obese rat livers
}

\author{
Ying-li LU ${ }^{\S 1}$, Wen JING ${ }^{\S 2}$, Lian-shi FENG ${ }^{\dagger 1}$, Li ZHANG ${ }^{1}$, Jian-fang XU ${ }^{1}$, Tong-jian YOU ${ }^{3}$, Jing ZHAO ${ }^{\dagger 4}$ \\ ( ${ }^{1}$ Biology Center, China Institute of Sport Science, Beijing 100061, China) \\ ( ${ }^{2}$ Sport Science Research Center of Shandong Province, Jinan 250102, China) \\ $\left({ }^{3}\right.$ Department of Exercise and Health Sciences, University of Massachusetts Boston, Boston, MA 02125, USA) \\ $\left({ }^{4}\right.$ School of Life Sciences, Shandong University, Jinan 250100, China) \\ †E-mail: fengls98@126.com; zhaojing@sdu.edu.cn
}

Received Feb. 21, 2014; Revision accepted July 8, 2014; Crosschecked Aug. 15, 2014

\begin{abstract}
To investigate the effects of hypoxic exercise training on microRNA (miRNA) expression and the role of miRNA expression in regulating lipid metabolism, 20 dietary-induced obese SD rats were divided into a normoxic sedentary group $(\mathrm{N}, n=10)$ and a hypoxic exercise training group $(H, n=10)$. After four weeks, measurements were taken of body weight, body length, fat mass, serum lipid concentration, miRNAs differentially expressed in rat liver, and gene and protein expression levels of peroxisome proliferator activated receptor a (PPARa), fatty acid synthetase (FAS), and carnitine palmitoyl transferase 1A (CPT1A) in rat liver. Body weight, Lee's index, fat mass, fat/weight ratio, and serum levels of total cholesterol (TC) and high density lipoprotein cholesterol (HDL-C) were all significantly lower in the $\mathrm{H}$ group than in the $\mathrm{N}$ group $(P<0.01)$. Six miRNAs expressed significantly differently in the liver $(P<0.05)$. Specifically, expression levels of miR-378b were significantly lower in the $\mathrm{H}$ group than in the $\mathrm{N}$ group $(P<0.05)$. Compared with the normoxic sedentary group, hypoxic exercise training resulted in a lower ratio of FAS mRNA to CPT1A mRNA $(P<0.05)$, as well as lower CPT1A protein levels $(P<0.01)$, while a higher ratio of FAS to CPT1A protein levels $(P<0.01)$ was observed. In conclusion, hypoxic training may elevate the resistance of high fat diet induced obesity in rats by reducing the expression of miR-378b, and decrease the fatty acid mitochondrial oxidation in obese rat livers by decreasing the protein expression of $C P T 1 A$ and increasing the protein expression ratio of FAS/CPT1A.
\end{abstract}

Key words: Hypoxic training, Obese rat, Liver, MicroRNA, Lipid metabolism

doi:10.1631/jzus.B1400052 Document code: A CLC number: R87

\section{Introduction}

Our previous studies have demonstrated that hypoxic exposure and hypoxic training reduce body weight (Huang et al., 2007; Feng and Lu, 2012; Lu et al., 2012) and serum lipid levels (Lu et al., 2013). Other studies have indicated that sea level residents lost body weight during their acute exposure to highaltitude hypoxia (Ge et al., 2010), which induced a

\footnotetext{
$\$$ Corresponding authors

$\S$ The two authors contributed equally to this work

* Project supported by the Science Foundation for the Youth of China Institute of Sport Science (CISS) (No. 13-19)

(C) Zhejiang University and Springer-Verlag Berlin Heidelberg 2014
}

weight loss due approximately $2 / 3$ rds to fat loss and 1/3rd to lean mass loss (Armellini et al., 1997). Mild physical exercise in normobaric hypoxia for eight weeks led to a significantly greater weight loss in obese persons than exercise in sham hypoxia (Netzer et al., 2008). Moderate intermittent hypoxic training reduced body weight by increasing leptin concentration and enhancing liver leptin expression, and also prevented steatosis in liver cells (Ling et al., 2008). Intermittent hypobaric hypoxia lowered plasma total cholesterol (TC), low density lipoprotein cholesterol (LDL-C), very low density lipoprotein cholesterol (VLDL-C), and triglyceride (TG) concentrations in coronary heart disease patients with abnormal lipid 
metabolism, while the high density lipoprotein cholesterol (HDL-C) level increased (Tin'kov and Aksenov, 2002).

A major mechanism underlying physiological remodeling is the regulation of genes and their products (Schlichting and Smith, 2002). Hypoxic exposure and hypoxic training are stressors to an organism and may cause gene expression to change, including genes related to lipid metabolism. Inbred mice exposed to more severe hypoxia (simulated altitude of $4500 \mathrm{~m}$ ) were smaller in mass than mice exposed to less severe hypoxia. Genes were significantly differentially expressed in response to chronic hypoxia. These genes are involved in angiogenesis, glycolysis, lipid metabolism, carbohydrate metabolism, and protein amino acid phosphorylation (Baze $e t$ al., 2010). Endurance training lessens chronic hypoxiainduced impairments in mitochondrial fatty acid oxidation mostly mediated by the activity of the long chain mitochondrial fatty acid transporter muscle carnitine palmitoyl transferase 1 (mCPT-1) rather than by mCPT-1 content (Galbès et al., 2008). Hypoxic training for three weeks regulated the lipid metabolism by reducing the mRNA and protein expression of sterol regulatory element binding protein- $1 \mathrm{c}$ in the obese rat liver (Wang et al., 2012).

MicroRNAs (miRNAs) are small single strand no-coding RNAs that repress gene expression through sequence-specific hybridization to complementary target sites in the 3'-untranslated regions (3' UTRs) of mRNA (Ambros, 2004; Filipowicz et al., 2008; Bartel, 2009). A single miRNA can simultaneously regulate the expression of multiple target genes, thereby providing a mechanism to regulate entire networks of genes. To date, miRNAs have been shown to play an integral role in numerous biological processes, including immune response, development, stem cell differentiation, and lipid metabolism. Current studies support the fact that miR-122 and miR-33 regulate cholesterol and fatty acid metabolisms (Moore et al., 2010), and miR-370 affects lipid metabolism through the regulation of miR-122 expression (Iliopoulos et al., 2010). In addition, miR-378/378*, miR-27, miR-103/ 107 , and miR-613 participate in the regulation of lipid metabolism (Lin et al., 2009; Gerin et al., 2010b; Ou et al., 2011; Trajkovski et al., 2011).

Training in mild hypoxia reduces body weight, lowers serum lipid concentrations, and regulates gene expression related to lipid metabolism in the liver and muscle of animals and humans. However, the underlying molecular mechanisms are still unknown. Therefore, the purpose of this study is to investigate the effects of concurrent hypoxic and endurance training on miRNA expression and lipid metabolism in obese rat livers.

\section{Materials and methods}

\subsection{Animals and treatments}

All procedures were approved by the Animal Care and Use Committee of the China Institute of Sport Science. Sixty male SD rats at three weeks of age were purchased from the Vital River Laboratory Animal Technology Co., Ltd., Beijing, China. All rats were housed at $(22.0 \pm 0.5){ }^{\circ} \mathrm{C}$ in standard cages with a $12 \mathrm{~h}: 12 \mathrm{~h}$ light-dark cycle. The animals were fed standard rat chow and tap water ad libitum for a week. Then rats weighing $(92 \pm 6) \mathrm{g}$ were separated into two groups: the control animals (C group, $n=15$ ) receiving standard rat chow (fat content: 10\% of energy) and the other animals (HF group, $n=45$ ) receiving a high-fat diet (fat content: $40 \%$ of energy). The high-fat diet contained $40 \%$ carbohydrates, $40 \%$ fat, and $20 \%$ protein, in comparison to the control diet, which contained $60 \%$ carbohydrates, $10 \%$ fat, and $30 \%$ protein. The high-fat diet was designed to induce hyperphagia, resulting in a greater energy intake compared with the control diet. After 12 weeks of feeding, the HF group showed a $10 \%$ greater average weight than the $\mathrm{C}$ group. We selected 10 rats randomly from each group, measured body weight and length to calculate Lee's index (Lee's index= $\frac{\sqrt[3]{\text { body weight }}}{\text { body length }} \times 1000$ ), and weighed the perirenal fat and epididymis fat to calculate the ratio of body fat to body weight. Lee's index, fat mass, and body fat/body weight ratio were all significantly elevated $(P<0.05)$ in the HF group, demonstrating that an obese fat model was successfully established.

\subsection{Hypoxic exercise training}

The remaining obese rats exercised on a treadmill for two weeks to adapt to the training program. The training speed elevated from 16 to $25 \mathrm{~m} / \mathrm{min}$, and the exercise time increased from 20 to $60 \mathrm{~min} / \mathrm{d}$ over 
two weeks. We selected 20 rats according to body weight and movement ability, and assigned them randomly into a normoxic sedentary group $(\mathrm{N}, n=10)$ or hypoxic training group $(\mathrm{H}, n=10)$. All 20 animals continued to be fed the high-fat diet. Rats in the $\mathrm{N}$ group lived in normoxic conditions (21\% oxygen) without exercise, while the rats in the $H$ group lived in a $13.6 \%$ oxygen condition (equivalent to an altitude of $3500 \mathrm{~m}$ ), and trained for $20 \mathrm{~m} / \mathrm{min}$ for $1 \mathrm{~h}$ a day, $6 \mathrm{~d}$ per week for 4 weeks. The rats were four months old at the start of the training, equivalent to that of teenagers in humans.

\subsection{Sample collection}

For the rats in the $\mathrm{H}$ group, sample collection was scheduled to be 24-36 h after the last session of exercise training to eliminate the effect of acute exercise. After an overnight fast, rats in the two groups were weighed and then anesthetized with an intraperitoneal injection of $10 \%$ chloral hydrate $(0.3 \mathrm{ml} / 100 \mathrm{~g}$ body weight). Then body length of each rat was measured to calculate the Lee's index. Blood samples were collected from the aortaventralis, centrifuged, and kept frozen at $-80{ }^{\circ} \mathrm{C}$ until chemical assays. The right lobe of the rat liver was removed, frozen in liquid nitrogen, and stored in a $-80{ }^{\circ} \mathrm{C}$ freezer. The perirenal fat and epididymis fat were excised and washed in precool saline, then dried using filter paper, and weighed to calculate the ratio of body fat to body weight.

\subsection{Serum lipid tests}

Serum levels of fasting TC, TG, HDL-C, LDL-C, and free fatty acid (FFA) were measured using enzymatic methods with a fully automatic biochemical analyzer (BAYER ADVIA-2400).

\section{5 miRNA microarray hybridization and data analysis}

Total RNA samples were randomly selected, with three samples from each group ( $\mathrm{N}$ and $\mathrm{H}$ groups). The quality of the total RNA was evaluated on an Agilent 2100 analyzer. miRNA microarray contained 722 rat mature miRNAs (miRBase 19.0; http://www.mirbase. org). Microarray assays were performed using a service provider (LC Sciences, Hangzhou, China). Total RNA samples (4-8 $\mu \mathrm{g}$ ) were 3'-extended with a poly(A) tail using poly(A) polymerase. An oligonucleotide tag was then ligated to the poly(A) tail for later fluorescent dye staining. Hybridization was performed overnight on a $\mu$ Paraflo microfluidic chip using a micro-circulation pump (Atactic Technologies, Houston, TX, USA). On the microfluidic chip, each detection probe consisted of a chemically modified nucleotide coding segment complementary to the target miRNA and a spacer segment of polyethylene glycol to extend the coding segment away from the substrate. The detection probes were made by in situ synthesis using photogenerated reagent (PGR) chemistry. The hybridization melting temperatures were balanced by chemical modifications of the detection probes. Hybridization used $100 \mu 16 \times$ SSPE buffer (0.90 mol/L NaCl, $60 \mathrm{mmol} / \mathrm{L} \mathrm{Na}_{2} \mathrm{HPO}_{4}, 6 \mathrm{mmol} / \mathrm{L}$ ethylenediaminetetraacetic acid (EDTA); $\mathrm{pH}$ 6.8) containing $25 \%$ formamide at $34{ }^{\circ} \mathrm{C}$. After RNA hybridization, tag-conjugating $\mathrm{Cy} 3$ dye was circulated through the microfluidic chip for dye staining. Fluorescence images were collected using a laser scanner (GenePix 4000B, Molecular Device) and digitized using the Array-Pro image analysis software (Media Cybernetics, Rockville, MD, USA). Data were analyzed by first subtracting the background and then normalizing the signals using a LOWESS filter (Locally-weighted Regression).

If the intensity of miRNA in one of the six samples (three controls and three hypoxic training samples) was $>32$, the miRNA was considered detectable (Chen et al., 2012). Significance analysis of microarrays was performed to identify the significantly altered miRNA. The miRNA with an absolute fold change (H/C group) $>1.5$ and $P<0.05$ was considered significantly different.

\subsection{Total RNA isolation and reverse transcription (RT)}

Total RNA was isolated from 16 samples of the two groups ( 8 samples were randomly selected from each group) using TRIZOL according to the manufacturer's instructions. Light absorption values were read at 230, 260, and $280 \mathrm{~nm}$ using spectrophotometry to determine purity and density. Agarose gel electrophoresis was tested using a $28 \mathrm{~S}: 18 \mathrm{~S}$ ratio to determine the purity and integrity of the total RNA sample.

An AMV first strand cDNA synthesis kit (ABI) was used for miRNA RT. Briefly, $5 \mu$ l of total RNAs were reverse-transcribed with $1 \mu \mathrm{l}$ of $\mathrm{miR}-378 \mathrm{~b}$ 
specific reverse-transcribe primer (miR-378b RT for detection of miR-378b; Table 1) or random primers $\mathrm{p}(\mathrm{dN})_{6}$ (for detection of mRNA) in $0.2 \mathrm{ml}$ reaction volume. The cDNA was then stored at $-20{ }^{\circ} \mathrm{C}$ until further analysis.

\subsection{Real-time polymerase chain reaction (PCR)}

SYBR Green real-time PCR assays were performed to detect the relative amount of miR-378b, peroxisome proliferator activated receptor $\alpha(P P A R \alpha)$, fatty acid synthetase $(F A S)$, and carnitine palmitoyl transferase 1A (CPT1A) in $0.2 \mathrm{ml}$ PCR reactions, containing $1 \mu \mathrm{l}$ RT products, $10 \mu \mathrm{l}$ SYBR Green qPCR Master Mix, and $0.5 \mu \mathrm{mol} / \mathrm{L}$ forward/reverse primers. Real-time PCR was performed using the LightCycler480 Software Setup (Roche, Basel, Switzerland). The reaction was incubated at $95{ }^{\circ} \mathrm{C}$ for 2 min, followed by 40 cycles of $10 \mathrm{~s}$ at $95^{\circ} \mathrm{C}$ and $40 \mathrm{~s}$ at $60{ }^{\circ} \mathrm{C}$. The relative expression of miRNA was normalized with U6, and the relative expression of mRNA was normalized with $\beta$-actin. Primers were designed for real-time PCR using the Primer Premier 5.0. The sequences of the forward and reverse primers used to quantify mRNA are shown in the Table 1 . The PCR assays were performed according to the user's manual. Fluorescent emission data were captured and levels of miRNA and mRNA were quantified using the critical threshold $\left(C_{\mathrm{T}}\right)$ value. The expression was quantitated based on the following formula: $F=2^{-\Delta \Delta C_{\mathrm{T}}}$, where $\Delta \Delta C_{\mathrm{T}}=\left(C_{\mathrm{T}(\mathrm{t}, \mathrm{H})}-C_{\mathrm{T}(\mathrm{h}, \mathrm{H})}\right)-\left(C_{\mathrm{T}(\mathrm{t}, \mathrm{N})}-C_{\mathrm{T}(\mathrm{h}, \mathrm{N})}\right)$, where $C_{\mathrm{T}(\mathrm{t}, \mathrm{H})}$ and $C_{\mathrm{T}(\mathrm{t}, \mathrm{N})}$ are the mean of the target gene in the $\mathrm{H}$ and $\mathrm{N}$ groups, respectively, and $C_{\mathrm{T}(\mathrm{h}, \mathrm{H})}$ and $C_{\mathrm{T}(\mathrm{h}, \mathrm{N})}$ are the mean of the housekeeping gene in the $\mathrm{H}$ and $\mathrm{N}$ groups, respectively.

\subsection{Protein expression levels detected by enzyme- linked immunosorbent assay (ELISA)}

Total protein was extracted from 16 samples in the two groups ( 8 samples were randomly selected from each group) using the tissue or cell total protein extraction kit (Sangon Biotech, Shanghai, China) according to the manufacturer's instructions. Total protein content of each sample was measured to determine the quantity. Then each sample was adjusted by diluent to have an equal total protein concentration. The protein expression levels of PPAR $\alpha$, FAS, and CPT1A were detected by ELISA. The diluted standards, samples, and second horseradish peroxidase
Table 1 Primers of reverse transcription (RT) and real-time PCR

\begin{tabular}{llc}
\hline \multicolumn{1}{c}{ Primer } & \multicolumn{1}{c}{ Sequence $\left(5^{\prime} \rightarrow 3^{\prime}\right)$} & $\begin{array}{c}\text { PL } \\
(\mathrm{bp})\end{array}$ \\
\hline miR-378b RT & $\begin{array}{c}\text { CTCAACTGGTGCGTGGAGTCGGC } \\
\text { AATTCAGTTGAGCTTCTGA }\end{array}$ & \\
miR-378b F & $\begin{array}{c}\text { ACACTCCAGCTGGGAGTGGACTTG } \\
\text { GAGTCA }\end{array}$ & 65 \\
miRNA R & TGGTGTCGTGGAGTCG & \\
U6 F & CTCGCTTCGGCAGCACA & 94 \\
U6 R & AACGCTTCACGAATTTGCGT & \\
$\beta$-actin F & CGTAAAGACCTCTATGCCAACA & 229 \\
$\beta$-actin R & CGGACTCATCGTACTCCTGCT & \\
PPAR $\alpha$ F & TCTGAAAGATTCGGAAACTGC & 146 \\
PPAR $\alpha$ R & CATGTATGACAAAAGGCGGAT & \\
FAS F & GATGAAGAGGGACCATAAAGATAAC & 157 \\
FAS R & CCACTTGATGTGAGGGGAGAT & \\
CPT1A F & CTGCTGTATCGTCGCACATTAG & 110 \\
CPT1A R & CGGGAAGTATTGAAGAGTCGC & \\
\hline
\end{tabular}

PL: product length; RT: reverse-transcribe primer; F: forward primer; R: reverse primer

(HRP)-conjugated antibody were added into ELISA plates, incubated $37{ }^{\circ} \mathrm{C}$ for $60 \mathrm{~min}$, and washed to remove unbound substance. Then the chromogenic solution was added and kept at $37^{\circ} \mathrm{C}$ for $15 \mathrm{~min}$ in the dark. Finally, the stop solution was added to the stop reaction. Absorbance of each well was measured, the linear regression equation of the standard curve was calculated from the concentration and the optical density (OD) value of the standards, and the concentrations of samples were calculated from the linear regression equation and their $\mathrm{OD}$ values.

\subsection{Statistical analysis}

Quantitative data were expressed as mean \pm standard deviation (SD). Data analysis was performed with an IBM SPSS statistical software version 19.0. Experimental results were analyzed by an independent samples $t$ test. The criterion for significance was $P<0.05$, and for high significance was $P<0.01$.

\section{Results}

\subsection{Body weight and fat mass}

The body weight, Lee's index, fat mass, and fat mass to body weight ratio in the $\mathrm{H}$ group were all significantly lower than those in the $\mathrm{N}$ group $(P<0.01)$. The body length between the two groups had no significant differences $(P>0.05$; Fig. 1). 

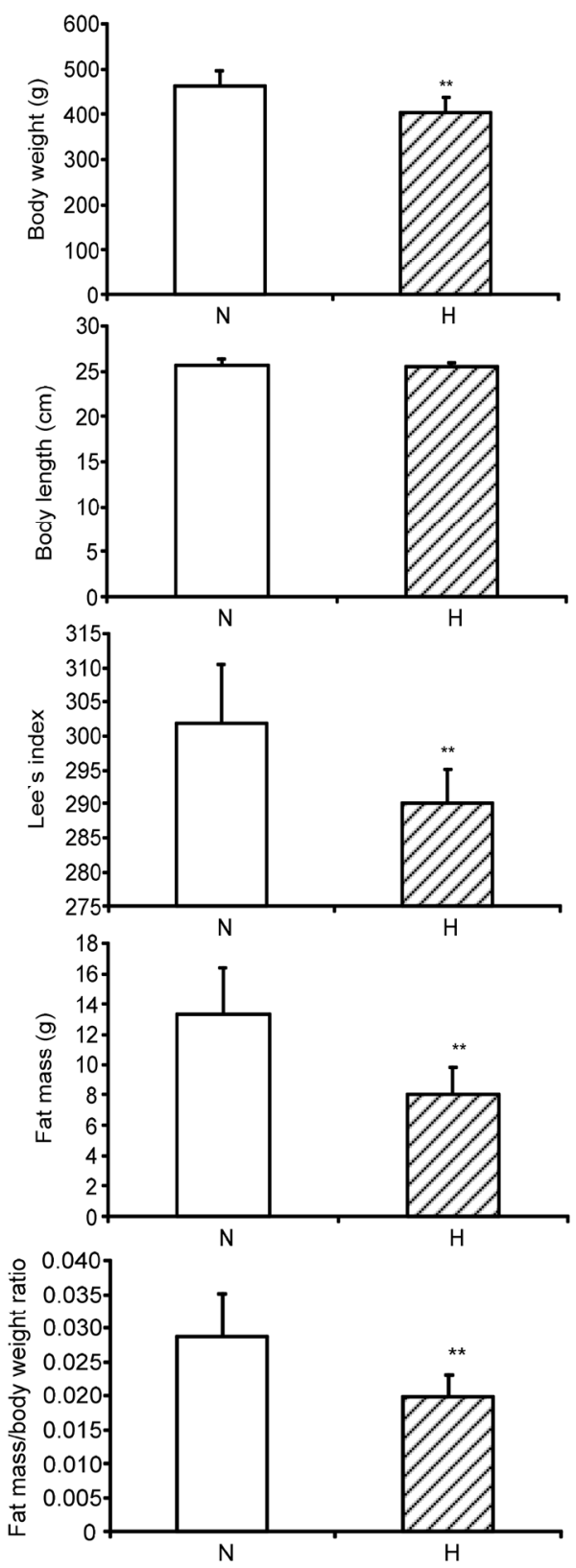

Fig. 1 Morphological index data in the $\mathrm{N}$ and $\mathrm{H}$ groups $\mathrm{N}$ : normoxic sedentary group; H: hypoxic training group. Experimental results were analyzed by an independent samples $t$ test. ${ }^{*} P<0.05,{ }^{* *} P<0.01, \mathrm{H}$ vs. $\mathrm{N}$ group. Data are expressed as mean $\pm \mathrm{SD}(n=10)$

\subsection{Serum TC and HDL-C}

Serum TC and HDL-C levels were significantly lower in the $\mathrm{H}$ group than in the $\mathrm{N}$ group $(P<0.01)$, serum TG and FFA levels were higher and the LDL-C level was lower in the $\mathrm{H}$ group than in the $\mathrm{N}$ group, while the difference between the two groups showed no statistical significance $(P>0.05$; Fig. 2$)$.
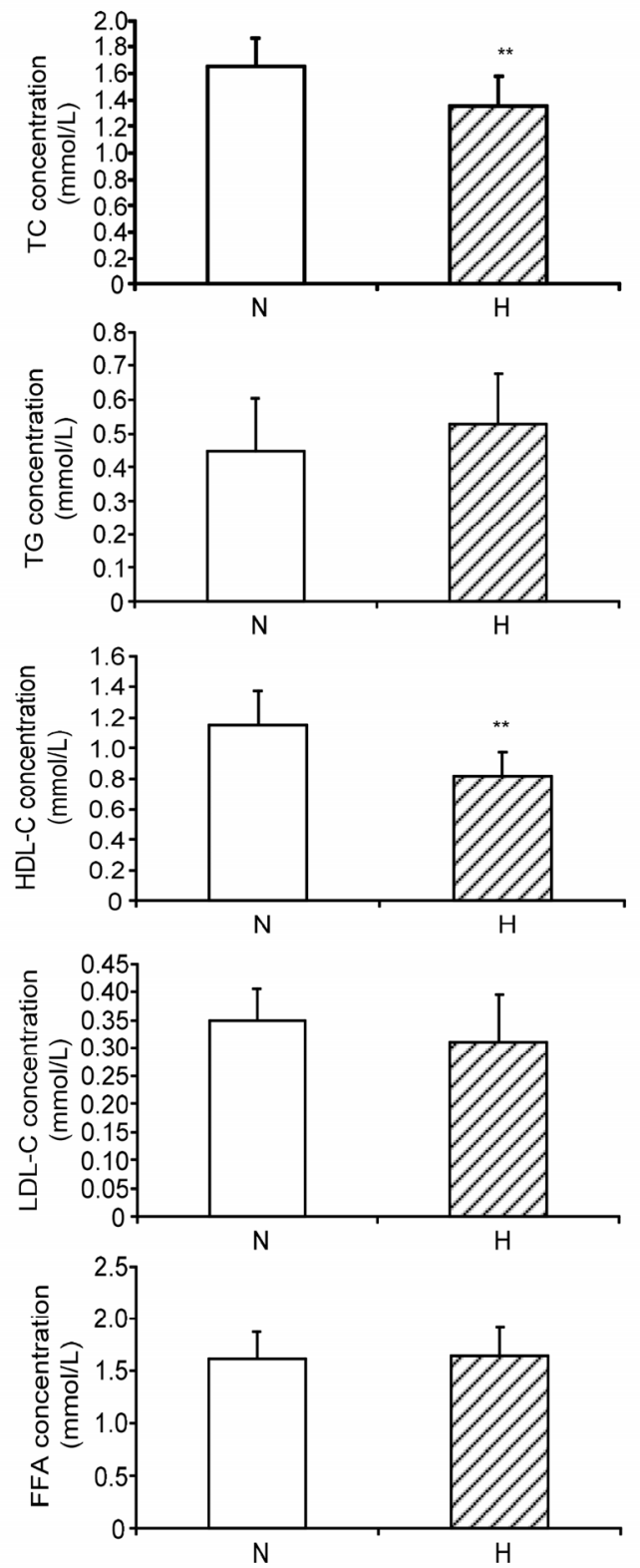

Fig. 2 Effects of hypoxic training on serum lipid concentrations

$\mathrm{N}$ : normoxic sedentary group; $\mathrm{H}$ : hypoxic training group. Experimental results were analyzed by an independent samples $t$ test. ${ }^{*} P<0.05,{ }^{* *} P<0.01, \mathrm{H}$ vs. $\mathrm{N}$ group. Data are expressed as mean $\pm \mathrm{SD}(n=10)$

\section{3 miRNA expression in the liver}

The expression levels of miRNAs were determined using a criterion of fold change $>1.5$ and $P<0.05$. miRNA microarray results showed that fold changes of the expression levels of 22 miRNAs in 722 mature miRNAs were $>1.5$ between the two groups, in which the expression levels of 8 miRNAs were 
lower and 14 miRNAs were higher in the $\mathrm{H}$ group than in the $\mathrm{N}$ group. The expression levels of 6 miRNAs were significantly different $(P<0.05)$ between the two groups, among which the miR-378b expression level was significantly lower and the others were significantly higher in the $\mathrm{H}$ group than in the $\mathrm{N}$ group (Table 2).

Table 2 miRNA expression in the $\mathrm{N}$ and $\mathrm{H}$ groups

\begin{tabular}{clccc}
\hline \multirow{2}{*}{ No. } & \multirow{2}{*}{ miRNA name } & \multicolumn{3}{c}{ miRNA expression } \\
\cline { 2 - 5 } & & $\mathrm{N}$ & $\mathrm{H}$ & $\mathrm{H} / \mathrm{N}$ \\
\hline 1 & rno-miR-3591 & $185 \pm 202$ & $36 \pm 8$ & 0.20 \\
2 & rno-miR-221-3p & $69 \pm 13$ & $38 \pm 19$ & 0.55 \\
3 & rno-miR-425-5p & $185 \pm 64$ & $111 \pm 48$ & 0.60 \\
4 & rno-miR-378b & $1429 \pm 239$ & $870 \pm 98^{*}$ & 0.61 \\
5 & rno-miR-3559-5p & $214 \pm 50$ & $136 \pm 22$ & 0.63 \\
6 & rno-miR-92b-3p & $454 \pm 157$ & $289 \pm 119$ & 0.63 \\
7 & rno-miR-106b-5p & $79 \pm 27$ & $52 \pm 12$ & 0.65 \\
8 & rno-miR-423-5p & $142 \pm 30$ & $92 \pm 32$ & 0.65 \\
9 & rno-let-7e-5p & $639 \pm 540$ & $967 \pm 318$ & 1.51 \\
10 & rno-miR-98-5p & $102 \pm 66$ & $156 \pm 71$ & 1.53 \\
11 & rno-miR-6215 & $126 \pm 46$ & $200 \pm 34$ & 1.59 \\
12 & rno-miR-30c-5p & $2190 \pm 960$ & $3516 \pm 1183$ & 1.61 \\
13 & rno-miR-466b-1-3p & $34 \pm 28$ & $59 \pm 33$ & 1.73 \\
14 & rno-miR-142-5p & $147 \pm 24$ & $256 \pm 56^{*}$ & 1.74 \\
15 & rno-miR-27a-3p & $157 \pm 104$ & $287 \pm 165$ & 1.83 \\
16 & rno-miR-494-3p & $475 \pm 19$ & $913 \pm 208^{*}$ & 1.92 \\
17 & rno-miR-802-5p & $648 \pm 222$ & $1320 \pm 392$ & 2.04 \\
18 & rno-miR-664-1-5p & $3113 \pm 3994$ & $6706 \pm 4750$ & 2.15 \\
19 & rno-miR-668 & $66 \pm 33$ & $149 \pm 10^{*}$ & 2.24 \\
20 & rno-miR-29b-3p & $271 \pm 43$ & $687 \pm 212^{*}$ & 2.53 \\
21 & rno-miR-100-5p & $326 \pm 94$ & $1031 \pm 370^{*}$ & 3.16 \\
22 & rno-miR-6216 & $418 \pm 293$ & $2813 \pm 3193$ & 6.73 \\
\hline & & &
\end{tabular}

Six significantly different-expression miRNAs were miR-378b, $142-5 p, 494-3 p, 668,29 b-3 p$, and $100-5 p$. Only the miR-378b was significantly lower in the $\mathrm{H}$ group than in the $\mathrm{N}$ group, and the others were all higher. Values are expressed as mean $\pm \mathrm{SD}(n=3)$. $\mathrm{N}$ : normoxic sedentary group; $\mathrm{H}$ : hypoxic training group. Experimental results were analyzed by an independent samples $t$ test. ${ }^{*} P<0.05,{ }^{* *} P<0.01, \mathrm{H}$ vs. $\mathrm{N}$ group

\subsection{Verification of miR-378b expression and mRNA levels of PPAR $\alpha, F A S$, and $C P T 1 A$ in the liver}

miR-378 had been demonstrated to participate in lipid metabolism, and its expression was verified by a real-time PCR. The results showed that the miR-378b expression level in the liver of the $\mathrm{H}$ group was significantly lower $(P<0.05)$ than that in the $\mathrm{N}$ group (Fig. 3), which was in accordance with the results of the miRNA microarray.
The mRNA expression levels of PPAR $\alpha, F A S$, and $C P T 1 A$ in the $\mathrm{H}$ group were all higher than those in the $\mathrm{N}$ group, none of the differences reached statistical significance, while the ratio of $F A S / C P T 1 A$ was significantly lower $(P<0.05)$ in the $\mathrm{H}$ group than in the $\mathrm{N}$ group (Fig. 3).
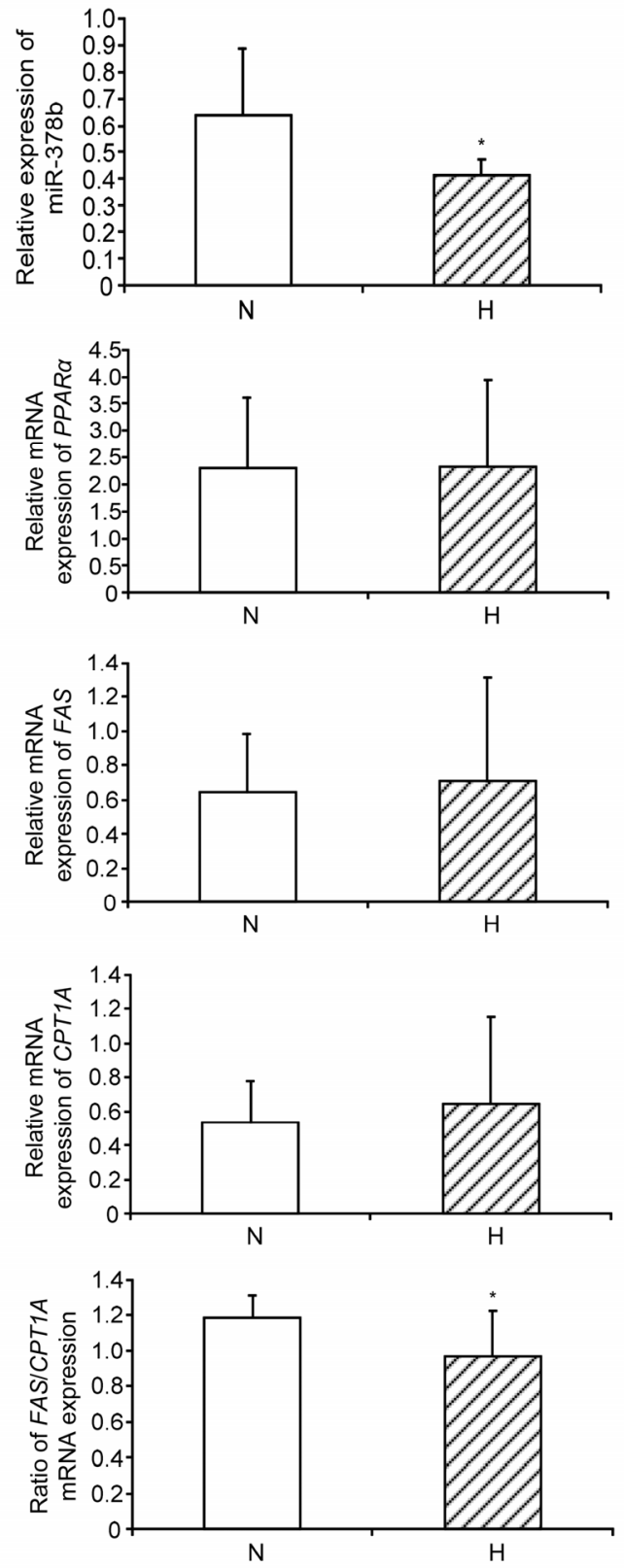

Fig. 3 Relative expression of miRNA and mRNA in the liver detected by real-time PCR

$\mathrm{N}$ : normoxic sedentary group; H: hypoxic training group. Experimental results were analyzed by an independent samples $t$ test. ${ }^{*} P<0.05,{ }^{* *} P<0.01, \mathrm{H}$ vs. N group. Data are expressed as mean $\pm \mathrm{SD}(n=8)$ 


\subsection{Effects of hypoxic exercise training on protein levels of PPARa, FAS, and CPT1A}

The protein expression levels of PPAR $\alpha$ and FAS in the $\mathrm{H}$ group were respectively lower and higher than those in the $\mathrm{N}$ group, but none of the differences showed statistical significance $(P>0.05)$, while the CPT1A expression was significantly lower $(P<0.01)$ in the $\mathrm{H}$ group than in the $\mathrm{N}$ group. The ratio of FAS and CPT1A protein levels was significantly higher $(P<0.01)$ in the $\mathrm{H}$ group than in the $\mathrm{N}$ group (Fig. 4).
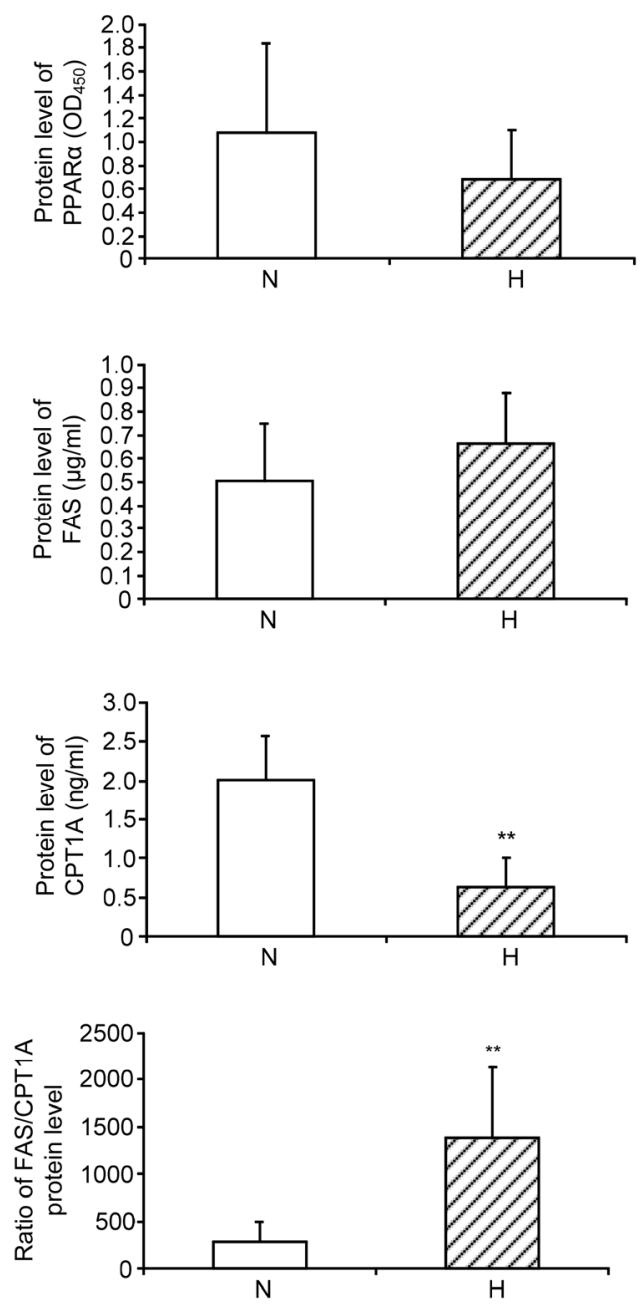

Fig. 4 Protein expression levels of PPARa, FAS, and CPT1A in the liver detected by ELISA

$\mathrm{N}$ : normoxic sedentary group; H: hypoxic training group. Experimental results were analyzed by an independent samples $t$ test. ${ }^{*} P<0.05,{ }^{* *} P<0.01, \mathrm{H}$ vs. $\mathrm{N}$ group. Data are expressed as mean $\pm \mathrm{SD}(n=8)$

\section{Discussion}

Lipid metabolism in the liver is very complex, which involves the synthesis and secretion of VLDL-C, and high rates of fatty acid synthesis and oxidation.

In this study, body weight, Lee's index, fat mass, and the fat mass to body weight ratio in the $\mathrm{H}$ group rats were all significantly lower than those in the $\mathrm{N}$ group, which was consistent with previous studies (Armellini et al., 1997; Netzer et al., 2008; Lippl et al., 2010). Armellini et al. (1997) thought that the reduction in energy intake may contribute to weight loss in individuals undergoing high altitude training. Lippl et al. (2010) found that the body weight of obese men was significantly lower at a $2650 \mathrm{~m}$ altitude for $7 \mathrm{~d}$, which may be due to a significantly higher resting metabolic rate and leptin level. Our research demonstrated that hypoxic exercise training reduced body fat, suggesting that exercise training in hypoxic conditions may reduce body fat by increasing fatty acid utilization in obese rats.

Changes in serum lipid levels could be due to several reasons. Firstly, the fat mobilization was reduced due to hypoxia over time, so the serum levels of lipids were lower at the point of measurement. Secondly, the increased catecholamine levels during hypoxia led to reduced lipolysis and a depot of intracellular fat (Richalet et al., 1988; Strobel et al., 1996). In our current study, serum TC levels were significantly lower, and LDL-C levels tended to be lower in the $\mathrm{H}$ group than in the $\mathrm{N}$ group, indicating that hypoxic exercise training may lower hypercholesterolemia. Combining with our findings that hypoxic exercise can decrease body fat and the TG and FFA showed little non-statistically significant elevation, we concluded that endurance exercise in hypoxic conditions increased the body's energy expenditure, especially through fat oxidation. This could lead to an increase in fat mobilization, accelerate the TG and FFA release into the blood, improve fat utilization in other tissues, and eventually reduce the body fat and body weight.

miRNAs are key regulators at the posttranscriptional level of gene expression through binding to the 3' UTR of their target genes (Bartel, 2009). In mammals, miRNAs are predicted to control the activity of approximately $30 \%$ of all protein-coding 
genes (Friedman et al., 2009), and have been shown to participate in the regulation of almost every cellular process, including lipid metabolism. Previous studies indicated that inhibition of miR-122 in vivo lowered serum TC and TG levels, and reduced gene expression of fatty acid and cholesterol syntheses (Krützfeldt et al., 2005; Esau et al., 2006; Elmén et al., 2008). Iliopoulos et al. (2010) reported that miR-370 could regulate the expression of miR-122 and CPT1 $\alpha$ to change lipid metabolism. miR-33 contributes to the regulation of cholesterol homeostasis by inhibiting cholesterol export and fatty acid oxidation (Gerin et al., 2010a; Najafi-Shoushtari et al., 2010; Rayner et al., 2010), and inhibition of miR-33 raises plasma HDL, lowers VLDL TGs, and promotes reverse cholesterol transport (Rayner et al., 2011a; 2011b). miR-378 and miR-378* are encoded by the first intron of a peroxisome proliferator-activated receptor- $\gamma$ coactivator-1 $\beta(P G C-1 \beta)$ gene and coexpressed with $P G C-1 \beta$ (Eichner et al., 2010). miR-378, miR-378*, and $P G C-1 \beta$ are up-regulated in the liver responding to a higher fat diet. Deletion of miR-378 and miR-378* can result in resistance to a high-fat-diet induced obesity and exhibit increased energy expenditure and mitochondrial oxidative capacity in mice (Carrer et al., 2012; Ishida et al., 2013). The significant reduction in miR-378b in our study indicates that miR-378b may be a key miRNA that regulates lipid metabolism in a rat liver. This study demonstrated that hypoxic training can enhance the ability of resisting a high fat diet and increase energy expenditure and fatty acid oxidation through decreasing the expression of miR-378b in rat livers.

Previous studies supported that overexpression of miRNA378/378* may up-regulate a series of lipogenic genes levels through increasing expression of PPAR $\gamma 2$, and then increase the size of the lipid droplets and the production of TG (Gerin et al., 2010b). However, knock-down of miRNA378 and/or miRNA378* decreases accumulation of TG. Our results indicated that the protein level of CPT1A was significantly lower in the $\mathrm{H}$ group than in the $\mathrm{N}$ group, while the protein expression ratio of FAS/CPT1A was significantly higher in the $\mathrm{H}$ group than in the $\mathrm{N}$ group. Our previous study found that the CPT-1 mRNA level was significantly increased in gastrocnemius of obese rats after hypoxic training for four weeks (Feng et al., 2013). These findings suggest that hypoxic exercise training decreased fatty acid oxidation in the liver by reducing the CPT1A protein expression and enhancing the protein expression ratio of FAS/CPT1A, while increasing the fatty acid oxidation in gastrocnemius by increasing the CPT1A mRNA level. Skeletal muscle of rats during hypoxia training consumed more energy produced by fatty acid; while the liver is the major organ producing fatty acid, fatty acid oxidation in the liver was lower by decreasing the CPT1A protein level, which supplied more fatty acid to other organs. The fatty acid produced in the liver was utilized by muscle, which is the possible mechanism of hypoxic training lowering body fat and body weight.

In summary, hypoxic exercise training for four weeks reduced body weight, fat mass, and serum TC concentrations in obese rats. Hypoxic training may elevate the resistance of a high-fat-diet induced obesity in the rats by reducing the expression of miR-378b, and decrease the ability of fatty acid mitochondrial oxidation in the obese rat liver by decreasing the protein expression of CPT1A and increasing the protein expression ratio of FAS/CPT1A.

\section{Limitations}

In this paper, the limitation noted is a lack of any study on the target genes of miR-378b. The next plan is to predict the target genes of miR-378b and detect their expression levels, then to verify the relationship between miR-378b and the different expression genes using the method of luciferase reporter gene, to find out the molecular mechanism of hypoxic training in regulating lipid metabolism by miR-378b in the liver.

\section{Compliance with ethics guidelines}

Ying-li LU, Wen JING, Lian-shi FENG, Li ZHANG, Jian-fang XU, Tong-jian YOU, and Jing ZHAO declare that they have no conflict of interest.

All institutional and national guidelines for the care and use of laboratory animals were followed.

\section{References}

Ambros, V., 2004. The functions of animal microRNAs. $\mathrm{Na}$ ture, 431(7006):350-355. [doi:10.1038/nature02871]

Armellini, F., Zamboni, M., Robbi, R., et al., 1997. The effects of high altitude trekking on body composition and resting metabolic rate. Horm. Metab. Res., 29(9):458-461. [doi:10.1055/s-2007-979077] 
Bartel, D.P., 2009. MicroRNAs: target recognition and regulatory functions. Cell, 136(2):215-233. [doi:10.1016/j.cell. 2009.01.002]

Baze, M.M., Schlauch, K., Hayes, J.P., 2010. Gene expression of the liver in response to chronic hypoxia. Physiol. Genomics, 41(3):275-288. [doi:10.1152/physiolgenomics. 00075.2009]

Carrer, M., Liu, N., Grueter, C.E., et al., 2012. Control of mitochondrial metabolism and systemic energy homeostasis by microRNAs 378 and $378^{*}$. PNAS, 109(38): 15330-15335. [doi:10.1073/pnas.1207605109]

Chen, T., Li, Z., Yan, J., et al., 2012. MicroRNA expression profiles distinguish the carcinogenic effects of riddelliine in rat liver. Mutagenesis, 27(1):59-66. [doi:10.1093/ mutage/ger060]

Eichner, L.J., Perry, M.C., Dufour, C.R., et al., 2010. miR-378(*) mediates metabolic shift in breast cancer cells via the PGC-1 $\beta / E R R \gamma$ transcriptional pathway. Cell Metab., 12(4):352-361. [doi:10.1016/j.cmet.2010.09.002]

Elmén, J., Lindow, M., Schütz, S., et al., 2008. LNA-mediated microRNA silencing in non-human primates. Nature, 452(7189):896-899. [doi:10.1038/nature06783]

Esau, C., Davis, S., Murray, S.F., et al., 2006. miR-122 regulation of lipid metabolism revealed by in vivo antisense targeting. Cell Metab., 3(2):87-98. [doi:10.1016/j.cmet. 2006.01.005]

Feng, L.S., Lu, Y.L., 2012. Altitude Training in China. International Convention on Science, Education and Medicine in Sport. Glasgow, UK, PSU32.06.

Feng, L.S., Lu, Y.L., Zhang, L., et al., 2013. Effect of hypoxic training on fatty acid oxidation in obese rats. FASEB J., 27:1b760.

Filipowicz, W., Bhattacharyya, S.N., Sonenberg, N., 2008. Mechanisms of post-transcriptional regulation by microRNAs: are the answers in sight? Nat. Rev. Genet., 9(2):102-114. [doi:10.1038/nrg2290]

Friedman, R.C., Farh, K.K., Burge, C.B., et al., 2009. Most mammalian mRNAs are conserved targets of microRNAs. Genome Res., 19(1):92-105. [doi:10.1101/gr.082701.108]

Galbès, O., Goret, L., Caillaud, C., et al., 2008. Combined effects of hypoxia and endurance training on lipid metabolism in rat skeletal muscle. Acta Physiol., 193(2): 163-173. [doi:10.1111/j.1748-1716.2007.01794.x]

Ge, R.L., Wood, H., Yang, H.H., et al., 2010. The body weight loss during acute exposure to high-altitude hypoxia in sea level residents. Acta Physiol. Sin., 62(6):541-546.

Gerin, I., Clerbaux, L.A., Haumont, O., et al., 2010a. Expression of miR-33 from an SREBP2 intron inhibits cholesterol export and fatty acid oxidation. J. Biol. Chem., 285(44):33652-33661. [doi:10.1074/jbc.M1 10.152090]

Gerin, I., Bommer, G.T., McCoin, C.S., et al., 2010b. Roles for miRNA-378/378* in adipocyte gene expression and lipogenesis. Am. J. Physiol. Endocrinol. Metab., 299(2): E198-E206. [doi:10.1152/ajpendo.00179.2010]

Huang, X.G., Feng, L.S., Xu, J.F., et al., 2007. Changes of body weight and energy metabolism of SD rats during hypoxic training. China Sport Sci., 27(10):61-68 (in Chinese). [doi:10.3969/j.issn.1000-677X.2007.10.007]

Iliopoulos, D., Drosatos, K., Hiyama, Y., et al., 2010. MicroRNA-370 controls the expression of microRNA-122 and Cpt1 $\alpha$ and affects lipid metabolism. J. Lipid Res., 51(6):1513-1523. [doi:10.1194/jlr.M004812]

Ishida, M., Shimabukuro, M., Yagi, S., et al., 2013. MicroRNA miR-378 regulates adipocytokine fate by targeting transcriptional factors in human isceral and subcutaneous adipose tissue. Eur. Heart J., 34(Suppl. 1): 604. [doi:10.1093/eurheartj/eht309.P3262]

Krützfeldt, J., Rajewsky, N., Braich, R., et al., 2005. Silencing of microRNAs in vivo with 'antagomirs'. Nature, 438(7068): 685-689. [doi:10.1038/nature04303]

Lin, Q., Gao, Z., Alarcon, R.M., et al., 2009. A role of miR-27 in the regulation of adipogenesis. FEBS J., 276(8): 2348-2358. [doi:10.1111/j.1742-4658.2009.06967.x]

Ling, Q., Sailan, W., Ran, J., et al., 2008. The effect of intermittent hypoxia on bodyweight, serum glucose and cholesterol in obesity mice. Pak. J. Biol. Sci., 11(6):869-875. [doi:10.3923/pjbs.2008.869.875]

Lippl, F.J., Neubauer, S., Schipfer, S., et al., 2010. Hypobaric hypoxia causes body weight reduction in obese subjects. Obesity, 18(4):675-681. [doi:10.1038/oby.2009.509]

Lu, Y.L., Feng, L.S., Zhao, P., 2012. Effect of Different Hypoxic Training on Body Weight in Rats. International Convention on Science, Education and Medicine in Sport. Glasgow, UK, PSU9.08.

Lu, Y.L., Zhang, L., Feng, L.S., et al., 2013. Effects of hypoxic training on serum lipoprotein of obese rats. FASEB J., 27: $1 b 769$.

Moore, K.J., Rayner, K.J., Suárez, Y., et al., 2010. MicroRNAs and cholesterol metabolism. Trends Endocrinol. Metab., 21(12):699-706. [doi:10.1016/j.tem.2010.08.008]

Najafi-Shoushtari, S.H., Kristo, F., Li, Y., et al., 2010. MicroRNA-33 and the SREBP host genes cooperate to control cholesterol homeostasis. Science, 328(5985): 1566-1569. [doi:10.1126/science.1189123]

Netzer, N.C., Chytra, R., Küpper, T., 2008. Low intense physical exercise in normobaric hypoxia leads to more weight loss in obese people than low intense physical exercise in normobaric sham hypoxia. Sleep Breath., 12(2):129-134. [doi:10.1007/s11325-007-0149-3]

Ou, Z., Wada, T., Gramignoli, R., et al., 2011. MicroRNA hsa-miR-613 targets the human $L X R \alpha$ gene and mediates a feedback loop of LXR $\alpha$ autoregulation. Mol. Endocrinol., 25(4):584-596. [doi:10.1210/me.2010-0360]

Rayner, K.J., Suárez, Y., Dávalos, A., et al., 2010. miR-33 contributes to the regulation of cholesterol homeostasis. Science, 328(5985):1570-1573. [doi:10.1126/science. 1189862]

Rayner, K.J., Sheedy, F.J., Esau, C.C., et al., 2011a. Antagonism of miR-33 in mice promotes reverse cholesterol transport and regression of atherosclerosis. J. Clin. Invest., 121(7):2921-2931. [doi:10.1172/JCI57275] 
Rayner, K.J., Esau, C.C., Hussain, F.N., et al., 2011b. Inhibition of $\mathrm{miR}-33 \mathrm{a} / \mathrm{b}$ in non-human primates raises plasma HDL and lowers VLDL triglycerides. Nature, 478(7369): 404-407. [doi:10.1038/nature10486]

Richalet, J.P., Mehidioi, H., Rathat, C., et al., 1988. Acute hypoxia decreases cardiac response to catecholamines in exercising humans. Int. J. Sports Med., 9(2):157-162. [doi:10.1055/s-2007-1024997]

Schlichting, C.D., Smith, H., 2002. Phenotypic plasticity: linking molecular mechanisms with evolutionary outcomes. Evol. Ecol., 16(3):189-211. [doi:10.1023/A:101 9624425971]

Strobel, G., Neureither, M., Bärtsch, P., 1996. Effect of acute mild hypoxia during exercise on plasma free and sulphoconjugated catecholamines. Eur. J. Appl. Physiol. Occup. Physiol., 73(1-2):82-87. [doi:10.1007/BF00262 813]

Tin'kov, A.N., Aksenov, V.A., 2002. Effects of intermittent hypobaric on blood lipid concentrations in male coronary heart disease patients. High Alt. Med. Biol., 3(3):277-282. [doi:10.1089/152702902320604250]

Trajkovski, M., Hausser, J., Soutschek, J., et al., 2011. MicroRNAs 103 and 107 regulate insulin sensitivity. Nature, 474(7353):649-653. [doi:10.1038/nature10112]

Wang, J.H., Lu, Y.L., Feng, L.S., et al., 2012. Living high training high inhibits the SREBP-1c expression in obese rats liver. China J. Sports Med., 31(7):590-595 (in Chinese). [doi:10.3969/j.issn.1000-6710.2012.07.004]

\section{中文㭷要:}

本文题目：低氧训练对肥胖大鼠肝脏 microRNA 表达及脂代谢的影响

Effects of hypoxic exercise training on microRNA expression and lipid metabolism in obese rat livers

研究目的：研究低氧训练对肥胖大鼠肝脏 microRNA 表达的影响及对脂代谢的调节。

创新要点: 通过肝脏 microRNA 的表达以及脂代谢的变化, 揭示 microRNA 调节低氧训练肥胖大鼠脂代 谢的相关机制。

研究方法: 二十只高脂饮食致肥胖大鼠进入正式实验, 分为常氧安静组和低氧训练组, 观察 4 周后肥 胖大鼠形态指标 (图 1) 以及血脂的变化 (图 2), microRNA 微阵列芯片筛选低氧训练肥 胖大鼠肝脏中 722 个成熟 miRNA 表达的差异 (表 2)，利用实时苂光定量聚合酶链式反应 (PCR) 检测大鼠肝脏微小 RNA-378b (miR-378b) 和过氧化物酶体增殖物激活受体 $\alpha$ $(P P A R \alpha)$ 、脂肪酸合成酶 $(F A S)$ 、肉碱棕榈酰转移酶 $1 \mathrm{~A}(C P T 1 A)$ 的 mRNA 表达水平 （图 3）, 酶联免疫吸附测定（ELISA）法检测 PPAR $\alpha 、 F A S 、 C P T 1 A$ 的蛋白水平（图 4）。

重要结论: 低氧训练通过降低肥胖大鼠肝脏 miR-378b 的表达水平, 增加大鼠对高脂饮食诱导肥胖的抵 抗能力; 通过降低肝脏 CPT1A 蛋白表达水平, 增加 FAS/CPT1A 蛋白表达比例降低肥胖大 鼠肝脏脂肪酸的氧化能力。

关键词组：低氧训练；肥胖大鼠；肝脏； miRNA；脂代谢 